\title{
Quality attributes of French fries as affected by different coatings, frozen storage and frying conditions.
}

\author{
Kizito KF, Abdel-Aal MH, Ragab MH, Youssef MM* \\ Department of Food Science and Technology, Faculty of Agriculture, University of Alexandria, El-Shatby, 21545, \\ Alexandria, Egypt
}

\begin{abstract}
Potato strips treated with different coatings (Carboxymethyl cellulose (CMC), pectin, agar and chitosan) at concentrations of 1 and $2 \%$ then fried for various durations $(5,7,9,11$ and 13 minutes) were investigated for organoleptic and other quality parameters. Strips were submerged in coating solutions for 5 seconds prior deep fat frying. Frying for 11 and 13 minutes gave the most significantly accepted fries while all coating treated strips obtained lower sensory quality scores and the concentrations used did not significantly affect sensory parameters of strips $(p<0.05)$. Coatings reduced the amount of oil absorbed by strips by $12.93 \%$ (pectin), $11.71 \%$ (CMC), $8.28 \%$ (chitosan) and $5.25 \%$ (agar). Coating treatments and concentration significantly improved moisture retention of strips $(p<0.05)$. Strips treated with hydrocolloids at $1 \%$ and fried for 11 minutes revealed that texture and yellowness $\left(b^{*}\right)$ values were not significantly different from the control strips. Lightness $\left(L^{*}\right)$ values of treated strips were similar to the control strips except chitosan treated strips $(\mathbf{p}<0.05)$. Redness $\left(a^{*}\right)$ values of all coated strips were not significantly different from the control strips except agar coated strips.

In another study, potato strips were semi-fried at $170 \pm 5^{\circ} \mathrm{C}$ for 2 minutes followed by quick air blast freezing at $-32^{\circ} \mathrm{C}$ for 20 min and stored at $-18^{\circ} \mathrm{C}$ for 6 months. The effect of frozen storage duration on quality parameters was monitored every month. Data revealed that peroxide values $(\mathrm{PV})$ initially increased and later decreased with elongation of storage duration. Free fatty acid (FFA), thiobarbituric acid (TBA) and $p$-anisidine $(p-A V)$ values significantly increased with storage duration $(p<0.05)$. Total oxidation (totox) values increased with storage duration. The CMC coating treatment did not significantly lower PV, FFA and TBA values while $p$-AV values were significantly lowered during frozen storage $(p<0.05)$.
\end{abstract}

Keywords: Coatings, Frying duration, Oil uptake, Moisture content, Colour, Texture, Frozen storage duration, Lipid oxidation.

Accepted on December 08, 2017

\section{Introduction}

Deep fat frying is a food preparation technique that has been applied to many food products with the intention of improving their appearance, texture and flavour. A brief overview of some processes and complex reactions that simultaneously occur during frying is noteworthy. Upon $\mathrm{i}$ mmersion of the food product into heated oil usually at $150-190^{\circ} \mathrm{C}$ [1], the product surface temperature rapidly rises till moisture evaporation occurs and continues till complete drying of the product as in crisps while in French fries, the surface is dry and crispy and the inside is moist and tender. During frying, most of the oil is adhered to the product surface due to high vapour pressure in the pores. Such oil is predominantly sucked into product pores during the cooling stage, after frying [2-7]. The desirable colour of fried products is a result of the Maillard reaction which is also responsible for the formation acrylamide, a proven carcinogen in rodents and neurotoxin in man [8-9].

Frying remarkably increases energy content of food products through oil absorption and frequent consumption of fried products has been associated with health complications like obesity, cardiovascular diseases and diabetes [10]. Even though there is increased awareness about this health issue, the market for fried foods is still growing. Therefore, prior knowledge about factors that affect oil absorption is required so that they are optimized.

Published research work in this area revealed that frying temperature [11-15], frying time [16-18], product surface area [11,19-21], moisture content [9], oil type [13], frying technique [22], blanching and soaking treatments [23-25] all affected the final oil content and other quality parameters of fried products. Optimization of the aforementioned conditions is crucial in obtaining fried products of lower oil content and desired quality [26].

Various edible coating materials have been utilized in diverse fried food products to improve some quality attributes. Coating materials were initially used to improve quality and prolong the storage life of meat then, later extended to fresh, frozen and processed foods [27]. Pectin, whey protein, soy protein isolate, methyl cellulose (MC), carboxymethyl cellulose (CMC), hydroxypropylmethyl cellulose (HMPC), basil seed gum, salep, alginate, guar, tracanth, zedo, chitosan, gellan gum, zein and xanthan gum have been used as coating materials in fried 
Citation: Kizito KF, Abdel-Aal MH, Ragab MH, et al. Quality attributes of French fries as affected by different coatings, frozen storage and frying conditions. J Agric Sci Bot 2017;1(1):18-24.

cassava, potato, banana, chick pea, green gram, shrimps, crust models, sev, chicken products [9,14,16,17,28-35]. Even though coated food products are much healthier due to their reduced oil contents, the use of coating materials should not significantly alter organoleptic properties of fried food products. Otherwise, coated foods might be rejected by consumers if any sensory quality attributes are deemed unacceptable.

In the present study, CMC, pectin, agar and chitosan solutions at different concentrations were utilized as coating materials for potato strips. Most fast food restaurants in the world sell fried potato strips (French fries) as preferred by their customers. For this reason, potato was used as a raw material in the present study. Effects of different coating materials, concentration and frying duration on oil uptake and organoleptic properties were investigated. In addition to that, the effect of frozen storage duration on quality parameters of semi fried strips was studied.

\section{Materials and Methods}

\section{Materials}

Potato tubers (Solanum tuberosum L., Hermes variety) used in the present study were generously provided by SONAC (Societe Nationale du Commerce) Company (Egypt) and chosen for its good frying qualities. Tubers were stored at $9^{\circ} \mathrm{C}$ and $95 \%$ relative humidity until use. $100 \%$ cotton seed oil, Fransawy (brand name) was provided by Extracted oil and Derivatives Company (Egypt).

\section{Coating materials}

Chitosan (93\% deacetylation), was manufactured by Oxford laboratory reagent while food grade carboxymethyl cellulose (CMC) was manufactured by Chungshu wealthy science and technology company (China) and imported by Redachem Egypt 1td. Agar was manufactured by Riedel-de haen ag seelze-hannover while pectin was manufactured by Navketau, India.

\section{Preparation of potato strips and coating solution}

Potato tubers were washed, hand peeled, cut into strips of $8 \times 8$ x $60 \mathrm{~mm}$ and i mmediately rinsed with water to get rid of surface starch and prevent enzymatic browning. Agar, CMC, low methoxyl pectin (LMP) and chitosan coating solutions at concentrations of 1 and $2 \%$ in $500 \mathrm{ml}$ were prepared at room temperature while agar required boiling in distilled water to enable complete solubilization. The preparation of chitosan solutions involved adding chitosan to $1 \%$ lactic acid solution and continuously stirred with a magnetic stirrer for overnight to ensure complete solubilization. Thereafter, chitosan solutions were filtered with a cheese cloth to eliminate any impurities. A dipping solution of $0.1 \%$ calcium chloride was selected for use after coating with pectin.

\section{Dipping treatment and frying conditions}

Potato strips free from excess surface moisture were completely submerged for 5 seconds in the prepared coating solutions. Pectin coated strips were further submerged for 3 seconds in $0.1 \%$ calcium chloride solution. The excess coating solutions were drained from all coated strips. The Black \& Decker deep fryer (model EF 1220-B5) was filled with 1.1L of cotton seed oil and the average weight of strips maintained at $102.65 \pm 1.43 \mathrm{~g}$. The strips were placed in a wire basket to ensure effective contact between the strips and the oil. Furthermore, strips were covered with a wire net attached to small stainless steel weights to ensure that the strips are fully submerged in oil during frying.

Fresh cotton seed oil was used for each coating treatment and the mean frying temperature was $170 \pm 5^{\circ} \mathrm{C}$ for the entire frying duration. Samples were fried for different frying times $(5,7,9,11$ and 13 minutes). At the end of frying, the fryer basket was immediately shaken for 10 seconds and strips were cooled to room temperature. The oil level was either checked and replenished or changed after 1.5 hours of frying. All experiments were run in duplicates.

In another study, strips were semi fried for 2 minutes and quick frozen by means of quick air blast freezing at $-32^{\circ} \mathrm{C}$ for $20 \mathrm{~min}$, then packed in polyethylene bags and stored at $-18^{\circ} \mathrm{C}$ for 6 months. Oxidative and hydrolytic reactions were monitored every month during frozen storage.

\section{Analytical methods}

Moisture was determined according to [36] while oil extraction and determination from well fried strips were performed according to [37] method using a homogenizer (Tekmar tissumizer, type SDI 1810). For semi fried strips, oil extraction involved soaking in hexane and shaking for 30 minutes. The oil-solvent mixture was filtered through filter paper containing anhydrous $\mathrm{Na}_{2} \mathrm{SO}_{4}$ to get rid of any moisture. The oil-solvent mixture was separated using a rotatory vacuum evaporator type $349 / 2$ and the obtained oil sealed in glass tubes and analyzed.

Color of fried strips was measured within 30 minutes of frying using Hunter Lab Ultra scan Vis (USA) colorimeter and values for $\mathrm{L}^{*}$ (Lightness/darkness), $\mathrm{a}^{*}$ (redness /greenness) and $\mathrm{b}^{*}$ (yellowness or blueness) were obtained.

Texture of fried strips was measured by Brookfield CT3 texture analyser (USA) with TA-CJ fixture and $10 \mathrm{~kg}$ load cell. Compression tests were performed with strips placed $3 \mathrm{~mm}$ from the needle probe TA9 moving at $0.5 \mathrm{~mm} / \mathrm{s}$ and with 30 seconds holding time.

Sensory evaluation was performed by 10 panelists who are Faculty members of the Food Science and Technology Department, Alexandria University. Samples were rando mly coded before being served to panelists. Five sensory quality parameters (colour, texture, odour, taste and the general acceptability) were individually evaluated basing on a nine point hedonic scale (1: dislike extremely and 9: like extremely).

Peroxide value was determined according to IUPAC [38] method 2.501 while Thiobarbituric values were spectrophotometrically measured [39]. The AOAC [36] methods 2.504 and 940.28 were used in the determination of $p$ Anisidine and free fatty acid (FFA) values, respectively. 


\section{Statistical Analysis}

The analysis of variance was done using SAS 9.13 Statistical software for windows 10 . The means were compared using the least significant difference (LSD) test at a probability level of $95 \%$.

\section{Results and Discussion}

\section{Sensory evaluation}

Results presented in Table 1 reveal that uncoated (the control) strips gained the highest quality scores in all quality attributes compared to all coated samples. Similar observations were reported by in coated potato chips [9]. In terms of coating treatments, strips coated with pectin obtained the lowest scores of all sensory parameters while those coated with CMC had the highest scores for all sensory parameters except texture. Variations in the concentration of coating materials did not significantly alter sensory quality attributes of fried strips. Furthermore, strips fried for 13 minutes were most preferred by panelists even though their scores were not significantly different from those of strips fried for 11 minutes.

Table 1: Effect of coating materials, concentration and frying time on sensory evaluation of fried potato strips. Means with different superscript alphabets in the same column separated by shaded row represent significant difference at $5 \%$ level of significance $(p<0.05)$

\begin{tabular}{|c|c|c|c|c|c|}
\hline & Colour & Texture & Odour & Taste & General acceptability \\
\hline \multicolumn{6}{|c|}{ Coating materials } \\
\hline Control & $8.08 \pm 0.94^{a}$ & $7.23 \pm 1.46^{a}$ & $8.15 \pm 1.11^{a}$ & $7.55 \pm 1.31^{a}$ & $7.76 \pm 1.05^{a}$ \\
\hline CMC & $7.64 \pm 1.36^{b}$ & $7.01 \pm 1.65^{a}$ & $7.88 \pm 1.27 a^{b}$ & $7.48 \pm 1.45^{a . b}$ & $7.53 \pm 1.29^{a . b}$ \\
\hline Pectin & $7.25 \pm 1.55^{c}$ & $6.62 \pm 1.93^{b}$ & $7.19 \pm 1.88^{d}$ & $7.00 \pm 1.82^{c}$ & $7.13 \pm 1.1 .50^{c}$ \\
\hline Agar & $7.43 \pm 1.41^{b . c}$ & $7.02 \pm 1.69^{a}$ & $7.55 \pm 1.32^{\mathrm{c}}$ & $7.20 \pm 1.49^{b . c}$ & $7.35 \pm 1.28^{b . c}$ \\
\hline Chitosan & $7.52 \pm 1.43^{b . c}$ & $7.12 \pm 1.64^{a}$ & $7.77 \pm 1.28 \mathrm{~b} .^{c}$ & $7.31 \pm 1.53^{\text {a.b.c. }}$ & $7.45 \pm 1.35^{b}$ \\
\hline \multicolumn{6}{|c|}{$\%$ Concentration } \\
\hline 0 & $8.08 \pm .093^{a}$ & $7.23 \pm 1.46^{a}$ & $8.15 \pm 1.11^{\mathrm{a}}$ & $7.55 \pm 1.31^{\mathrm{a}}$ & $7.76 \pm 1.05^{a}$ \\
\hline 1 & $7.38 \pm 1.44^{b}$ & $6.90 \pm 1.76^{b}$ & $7.48 \pm 1.45^{b}$ & $7.15 \pm 1.63^{b}$ & $7.26 \pm 1.37^{b}$ \\
\hline 2 & $7.30 \pm 1.54^{b}$ & $6.94 \pm 1.81^{b}$ & $7.50 \pm 1.59^{b}$ & $7.23 \pm 1.63^{b}$ & $7.32 \pm 1.44^{b}$ \\
\hline \multicolumn{6}{|c|}{ Frying time (min) } \\
\hline 5 & $6.68 \pm 1.48^{d}$ & $5.57 \pm 1.66^{d}$ & $7.02 \pm 1.73^{d}$ & $6.05 \pm 1.66^{d}$ & $6.29 \pm 1.29^{d}$ \\
\hline 7 & $7.32 \pm 1.40^{c}$ & $6.20 \pm 1.48^{\mathrm{C}}$ & $7.32 \pm 1.53^{c}$ & $6.58 \pm 1.43^{c}$ & $6.89 \pm 1.19^{c}$ \\
\hline 9 & $7.73 \pm 1.19^{b}$ & $7.41 \pm 1.31^{b}$ & $7.84 \pm 1.38^{b}$ & $7.65 \pm 1.33^{b}$ & $7.72 \pm 1.18^{b}$ \\
\hline 11 & $8.13 \pm 1.00^{\mathrm{a}}$ & $7.88 \pm 1.16^{a}$ & $8.18 \pm 1.00^{a}$ & $8.08 \pm 0.95^{a}$ & $8.10 \pm 0.85^{a}$ \\
\hline 13 & $8.06 \pm 1.24^{a}$ & $7.98 \pm 1.29^{a}$ & $8.18 \pm 0.97^{a}$ & $8.18 \pm 0.91^{\mathrm{a}}$ & $8.21 \pm 0.86^{a}$ \\
\hline
\end{tabular}

\section{Coatings}

Results in Table 2 reveal that the moisture content of all coated strips was significantly $(\mathrm{p}<0.05)$ higher than that of uncoated potato strips. Similar results were obtained by $[29,34]$ while [27] explained that coating materials not only sacrifice their moisture but also act as roadblocks to moisture loss which resulted in higher moisture levels in coated food products.

Potato strips previously coated with $\mathrm{CMC}$ retained the highest moisture content among all coated strips. This is probably due to variations in coating mechanical strength and pick up which depends on the hydrocolloid viscosity. In addition to that, thermal gelation and high water holding capacity of CMC coatings enhanced barrier properties against moisture loss $[27,34]$. Moisture retention in pectin and agar coated strips was not significantly different $(\mathrm{p}<0.05)$ while chitosan coated strips retained the lowest moisture content among coated strips. This is probably due to the low water holding capacity and mechanical strength of chitosan coatings.

In terms of oil content, Table 2 shows that control strips absorbed significantly more oil $(\mathrm{p}<0.05)$ compared to all coated strips. Similar observations were reported by Garcia et al. [28], Rimac-Brncic et al. [29], Pahade \& Sakhale [33] and Hua et al. [9] in coated potato strips and Bajaj \& Singhal [30], Freitas et al. [31], Phule \& Annapure [14], Karimi \& Kenari [35] in other coated products. Moisture evaporation from food products during $\mathrm{i}$ mmersion frying damages the cellular structure of plant tissues causing increased porosity which contributes to oil absorption $[4,5,14,29]$ while thermal gelation or cross-linkage in coating materials cause moisture entrapment during frying and this in turn results in formation of fewer pores within which less oil is absorbed [35]. 
Citation: Kizito KF, Abdel-Aal MH, Ragab MH, et al. Quality attributes of French fries as affected by different coatings, frozen storage and frying conditions. J Agric Sci Bot 2017;1(1):18-24.

Among coating materials used, pectin and CMC coated strips showed no significant difference $(\mathrm{p}<0.05)$ in oil content and had the highest oil reduction effects about $12.93 \%$ and $11.71 \%$, respectively. The fact that these hydrocolloids had the highest moisture retention explains why they absorbed the lowest amount of oil. Even though coating strips with agar and chitosan reduced the oil content by 5.25 and $8.28 \%$, respectively, such coatings showed the least efficient oil barrier properties since they absorbed significantly $(\mathrm{p}<0.05)$ more oil than pectin and CMC coated strips.

Table 2: Effect of different coating materials on moisture and oil content of fried strips. Means with different superscript alphabets in the same column represent significant difference at 5\% level of significance $(p<0.05)$.

\begin{tabular}{llll}
\hline Coating & $\%$ Moisture content & $\begin{array}{l}\% \\
\text { content }\end{array}$ & $\begin{array}{l}\text { Oil } \\
\text { content }\end{array}$ \\
\hline Control & $48.49 \pm 11.10^{\mathrm{d}}$ & $9.90 \pm 1.29^{\mathrm{a}}$ & \\
\hline CMC & $53.43 \pm 9.07^{\mathrm{a}}$ & $8.74 \pm 1.82^{\mathrm{d}}$ & 11.71 \\
\hline Pectin & $49.74 \pm 10.11^{\mathrm{b}}$ & $8.62 \pm 1.74^{\mathrm{d}}$ & 12.93 \\
\hline Agar & $49.40 \pm 9.28^{\mathrm{b} . \mathrm{c}}$ & $9.38 \pm 1.91^{\mathrm{b}}$ & 5.25 \\
\hline Chitosan & $49.15 \pm 9.66^{\mathrm{c}}$ & $9.08 \pm 1.89^{\mathrm{c}}$ & 8.28 \\
\hline
\end{tabular}

\section{Concentration}

Generally, increasing the concentration of various coating solutions elevates moisture retention in coated strips (Figure 1a). Higher concentrations of coating are more viscous and have enhanced water holding capacities which improves surface barrier properties to moisture loss [31,34,35].

In terms of oil absorption, CMC and agar coated strips showed substantial reduction in oil content with increasing concentration (Figure 1b). Increasing the concentrations of such coatings elevates the water holding capacity which in turn results in decreased moisture loss. Since more moisture is retained, then a less porous surface structure was formed and this was responsible for the low oil absorption. On the other hand, higher concentrations of pectin and chitosan notably absorbed more oil. The adhesion of pectin coatings at increasing concentration is affected by calcium ion concentration which was also reported to affect oil absorption [27,9].

\section{Frying time}

Generally, moisture loss increases with elongation of the frying duration in both coated and uncoated potato strips (Figure 2a) just as it was reported by Gamble \& Rice [19], Debnath et al. [12], Kilincceker [16]. The moisture content of CMC coated strips was particularly higher than that for strips coated with other materials for all frying times. This is probably due to greater coating pickup which provides a thicker layer with excellent moisture barrier properties in CMC coated strips. Moisture loss trends in chitosan, pectin and agar coated strips were closely related when strips were fried for the same duration. The sudden drop in moisture content of uncoated strips after 7 minutes of frying was due to increased surface heat transfer and start of crust formation as explained by Pedreschi [7]. This resulted in much lower moisture content in uncoated strips fried for 9 and 11 minutes compared to all coated strips since coating materials as barriers to moisture loss $[28,34]$. After 13 minutes of frying, the final moisture content of uncoated and coated strips varied slightly with the exception of strips coated with CMC.

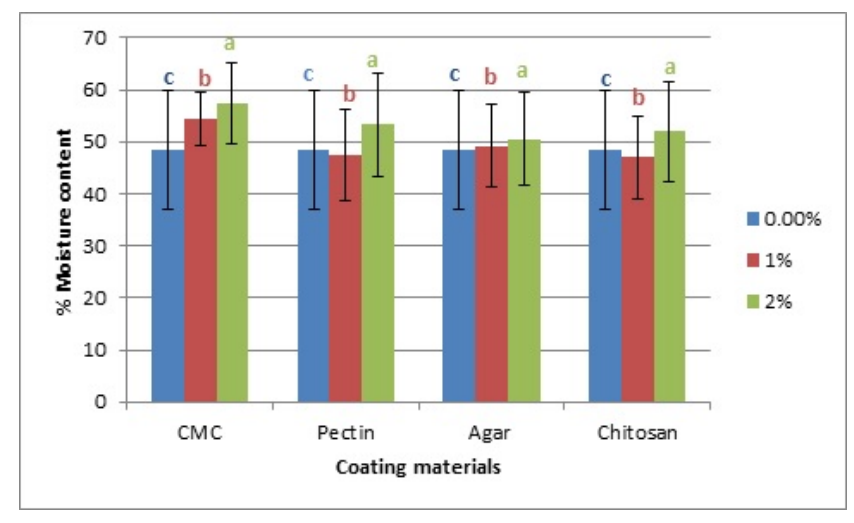

Figure 1a: Effect of concentration on the percentage moisture content of coated strips.

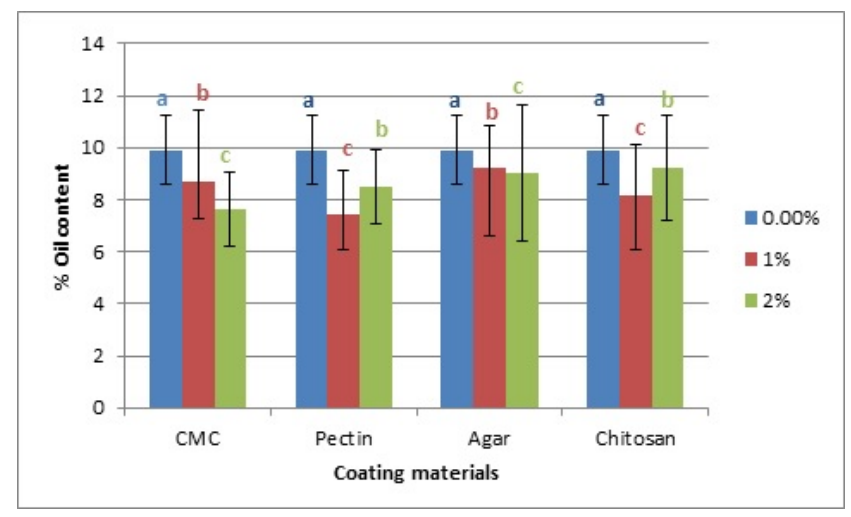

Figure 1b: Effect of concentration on the percentage oil content of coated strips.

The final oil content increased with frying time for both coated and uncoated potato strips (Figure 2b). This is due to the fact that elongation of the frying duration increases moisture loss which in turn creates more pores into which oil is absorbed [40]. All coated potato strips absorbed less oil than uncoated strips for all frying times except 13 minutes in agar coated strips. The frying duration remarkably altered oil barrier properties of some coating materials as seen in agar and pectin coated strips fried for more than 9 and 11 minutes, respectively.

\section{Texture}

When potato strips coated with different coating materials at $1 \%$ were fried for 11 minutes (optimum frying time) and analysed for colour and texture, observations in Table 3 were obtained. Hardness scores of all coated strips varied about the control with no significant difference $(p<0.05)$. Such results are in agreement with those obtained by Garcia et al. [28] and Bajaj \& Singhal [30]. 


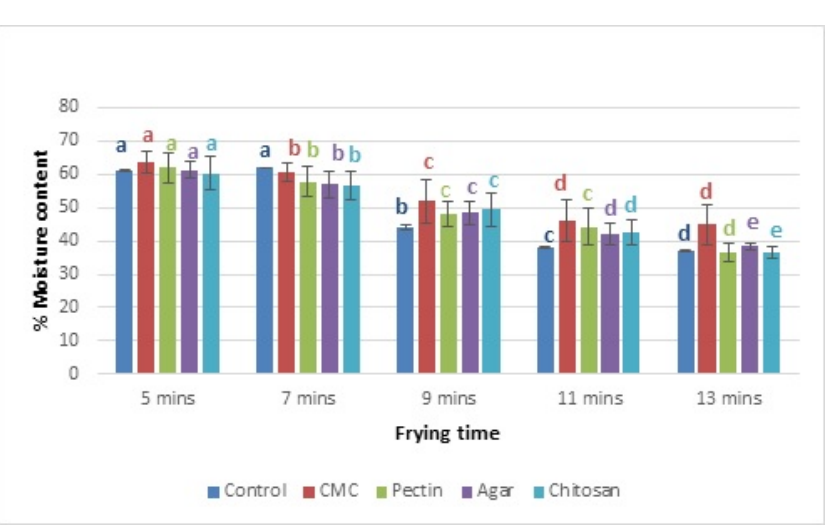

Figure 2a: Effect of frying time on the percentage moisture content of coated and uncoated strips.

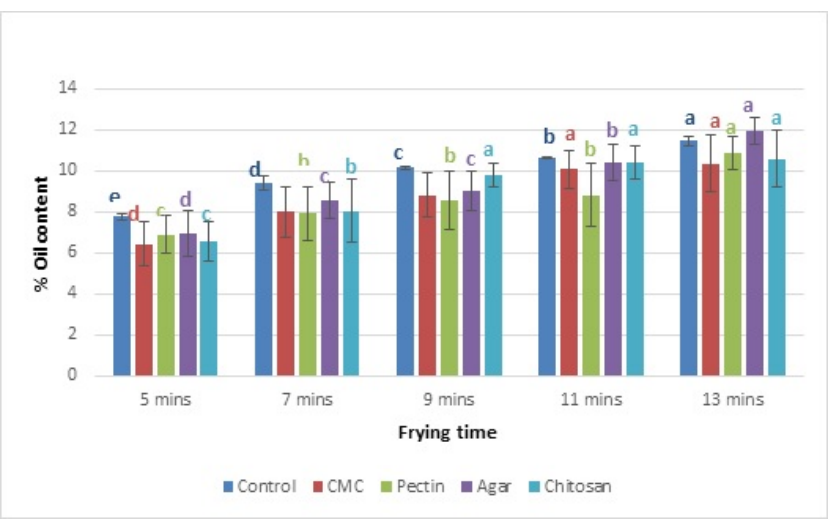

Figure 2b: Effect of frying time on the percentage oil content of coated and uncoated strips.

\section{Colour}

In terms of lightness, the control strips were not significantly different from all coated strips except chitosan coated strips (Table 3). The Maillard reaction was more severe in chitosan coated strips compared to strip coated with other materials. According to Ansarifar et al. [17], redness is a less preferable colour attribute in fried products. Redness $\left(\mathrm{a}^{*}\right)$ values of the control strips were not significantly different from all coated strips except agar coated strips. Yellowness is the most desired colour attribute in fried products. Obtained results show that coating treatments did not significantly alter the yellowness of fried strips. Similar observations were reported by Singthong \& Thongkaew [32] and Izadi et al. [34] in products coated with different hydrocolloids.

\section{Studies on semi fried strips during storage}

Frying in 2 phases (semi and then complete frying) increased oil content from 4.45 and $3.92 \%$ to 20.20 and $21.60 \%$ in the control and CMC coated strips, respectively. Such oil amounts were much higher than that in strips continuously fried in one phase for 13 minutes (Figure 2b). This was attributed to the fact that frying in two phases resulted in much higher moisture losses from 75.4 and $74.0 \%$ in semi fried strips to 38.4 and $40.2 \%$ in complete fried control and CMC coated strips, respectively.

Table 3: Effect of coating treatments on texture and colour parameters of fried potato strips. Means with different superscript alphabets in the same column represent significant difference at $5 \%$ level of significance $(p<0.05)$

\begin{tabular}{lllll}
\hline Coating & Hardness $/ \mathbf{N}$ & $\mathbf{L}^{*}$ value (Lightness) & $\mathbf{a}^{*}$ value (Redness) & b value (Yellowness) $^{*}$ \\
\hline Control & $0.11 \pm 0.12^{\mathrm{a}}$ & $58.99 \pm 2.25^{\mathrm{a} . \mathrm{b}}$ & $9.59 \pm 0.61^{\mathrm{a} . \mathrm{b}}$ & $27.34 \pm 2.47^{\mathrm{a}}$ \\
\hline CMC & $0.09 \pm 0.01^{\mathrm{a}}$ & $53.54 \pm 2.57^{\mathrm{b} . \mathrm{c}}$ & $9.72 \pm 0.44^{\mathrm{a} . \mathrm{b}}$ & $24.27 \pm 2.78^{\mathrm{a}}$ \\
\hline Pectin & $0.13 \pm 0.06^{\mathrm{a}}$ & $58.39 \pm 0.79^{\mathrm{a} . \mathrm{b}}$ & $7.62 \pm 1.87^{\mathrm{b} . \mathrm{c}}$ & $27.15 \pm 0.59^{\mathrm{a}}$ \\
\hline Agar & $0.10 \pm 0.04^{\mathrm{a}}$ & $60.16 \pm 1.97^{\mathrm{a}}$ & $6.51 \pm 1.29^{\mathrm{c}}$ & $26.95 \pm 0.26^{\mathrm{a}}$ \\
\hline Chitosan & $0.12 \pm 0.09^{\mathrm{a}}$ & $51.73 \pm 0.38^{\mathrm{c}}$ & $11.14 \pm 0.13^{\mathrm{a}}$ & $23.61 \pm 1.34^{\mathrm{a}}$ \\
\hline
\end{tabular}

Peroxide values (PV) significantly increased during the first three months of storage and did not significantly decrease till the fifth month of storage in both CMC and control strips (Table 4). The most significant decrease in PV occurred after six of storage. During storage, primary oxidation products (hydroperoxides) are initially formed and later decomposed to secondary oxidation products [41]. The CMC coating treatment did not significantly minimize the oxidation of strips during storage.

Free fatty acids (FFA) are formed through a nucleophilic attack at the ester bond of triacylglycerol and have been associated with undesirable tastes and odours [42]. Generally, FFA significantly increased with elongation of the storage duration
(Table 4). The CMC coating treatment did not significantly lower the FFA values of strips during frozen storage. All FFA values obtained during storage were within the range set for frozen potato strip by the CODEX standard.

Malondiadehyde is one of the secondary oxidation products formed after decomposition of hydroperoxides and is presented as TBA values. Elongation of the frozen storage duration generally increased TBA values and the most significant increase occurred after six months of storage (Table 4). The CMC coating treatments did not significantly $(\mathrm{p}<0.05)$ lower TBA values of strips during storage. 
Citation: Kizito KF, Abdel-Aal MH, Ragab MH, et al. Quality attributes of French fries as affected by different coatings, frozen storage and frying conditions. J Agric Sci Bot 2017;1(1):18-24.

The $p$-Anisidine value $(p$-AV) is a measure of secondary oxidation products specifically alkenals and 2,4-dieinals present in oil. $p$-AV significantly increased after five months of storage since prolonged storage results in decomposition of hydroperoxides to secondary oxidation products and this indicates advanced oxidation of lipids. The CMC coatings significantly reduced $p$-AV and this proved that the $\mathrm{CMC}$ coating treatment limited the production of some secondary oxidation products

Total oxidation (Totox) value is a summation of $2 \mathrm{PV}$ and $p-\mathrm{AV}$ and indicates the overall status of oil. Totox values initially decreased but later increased with elongation of the storage duration (Table 4). The CMC coating treatment generally decreased totox values during storage.

Table 4: Effect of cold storage duration and coating treatment on quality parameters of frozen semi fried strips. D: Not determined. Means with different superscript alphabet in the same column separated by shaded rows represent significant difference at $5 \%$ level of significance $(p<0.05)$.

\begin{tabular}{|c|c|c|c|c|c|c|c|c|}
\hline $\begin{array}{l}\text { Storage } \\
\text { time/ } \\
\text { months }\end{array}$ & PV & & FFA & & TBA & & $P$-AV & Totox \\
\hline 0 & $\begin{array}{l}10.06 \\
2.87^{b}\end{array}$ & \pm & $\begin{array}{l}0.19 \\
0.03^{c}\end{array}$ & \pm & N.D & & $\begin{array}{l}16.29 \\
12.48^{d}\end{array}$ & 36.41 \\
\hline 1 & $\begin{array}{l}11.88 \\
0.42^{a . b}\end{array}$ & \pm & $\begin{array}{l}0.10 \\
0.02^{c}\end{array}$ & \pm & $\begin{array}{l}51.72 \\
18.10^{c}\end{array}$ & \pm & $8.47 \pm 1.67^{e}$ & 32.23 \\
\hline 3 & $\begin{array}{l}12.50 \\
0.00^{a}\end{array}$ & \pm & $\begin{array}{l}0.18 \\
0.02^{\mathrm{C}}\end{array}$ & \pm & $\begin{array}{l}68.92 \\
1.56^{\mathrm{b}}\end{array}$ & \pm & $\begin{array}{l}17.39 \\
4.12^{\text {c.d }}\end{array}$ & 42.39 \\
\hline 4 & $\begin{array}{l}12.05 \\
0.17^{a . b}\end{array}$ & \pm & $\begin{array}{l}0.46 \\
0.0 .07^{b}\end{array}$ & \pm & $\begin{array}{l}52.00 \\
3.52^{\mathrm{c}}\end{array}$ & \pm & $19.81 \pm 5.97^{c}$ & 43.91 \\
\hline 5 & $\begin{array}{l}12.09 \\
0.43^{a . b}\end{array}$ & \pm & $\begin{array}{l}0.20 \\
0.07^{c}\end{array}$ & \pm & $\begin{array}{l}73.04 \\
4.98^{a . b}\end{array}$ & \pm & $\begin{array}{l}31.25 \\
13.22^{\mathrm{a}}\end{array}$ & 55.43 \\
\hline 6 & $\begin{array}{l}7.60 \\
1.76^{c}\end{array}$ & \pm & $\begin{array}{l}0.76 \\
0.15^{a}\end{array}$ & \pm & $\begin{array}{l}84.71 \\
11.40^{\mathrm{a}}\end{array}$ & \pm & $27.37 \pm 7.05^{\mathrm{b}}$ & 42.57 \\
\hline \multicolumn{9}{|l|}{$\begin{array}{l}\text { Coating } \\
\text { treatment }\end{array}$} \\
\hline Control & $\begin{array}{l}12.32 \\
2.56^{a}\end{array}$ & \pm & $\begin{array}{l}0.296 \\
0.27^{a}\end{array}$ & \pm & $\begin{array}{l}55.71 \\
26.75^{a}\end{array}$ & \pm & $\begin{array}{l}19.36 \\
14.80^{a}\end{array}$ & 44.00 \\
\hline $\mathrm{CMC}$ & $\begin{array}{l}11.25 \\
3.43^{a}\end{array}$ & \pm & $\begin{array}{l}0.263 \\
0.22^{\mathrm{a}}\end{array}$ & \pm & $\begin{array}{l}52.16 \\
28.88^{a}\end{array}$ & \pm & $15.38 \pm 8.49^{b}$ & 37.88 \\
\hline
\end{tabular}

\section{Conclusion}

In the light of data presented here, it can be concluded that $\mathrm{CMC}$ coating at $1 \%$ and frying at $170 \pm 5^{\circ} \mathrm{C}$ for 11 minutes was found to be the most proper conditions to produce French fries of the best quality in terms of sensory properties, reduction in oil uptake, texture and colour as assessed objectively and subjectively. Even though pectin coated strips were not significantly different from CMC coated strips in terms of oil content, such strips obtained the lowest sensory quality scores. All coating treatments significantly improved moisture retention. Frying in 2 phases (semi and later complete frying) resulted in higher oil absorption. The FFA and secondary oxidation products significantly increased with elongation of the storage duration while PV initially increased but later decreased with elongation of the storage duration. Total oxidation values increased with elongation of the storage duration. The CMC coating treatment did not offer significant reductions in FFA, $\mathrm{PV}$ and TBA values except $p$-anisidine values.

\section{Acknowledgements}

This research work was partly supported by the Nile Basin Initiative Scholarship in collaboration with Alexandria University.

\section{References}

1. Choe E, Min DB. Chemistry of deep-fat frying oils. J Food Sci. 2007;72:77-86.

2. Ufheil G, Escher F. Dynamics of oil uptake during deep-fat frying of potato slices. LWT-Food Sci and Tech. 1996;29:640-44.

3. Aguilera JM, Gloria-Hernandez H. Oil absorption during frying of frozen parfried potatoes. J Food Sci. 2000;65:476-79.

4. Mellema M. Mechanism and reduction of fat uptake in deep-fat fried foods. Trends in Food Sci Tech. 2003;14:364-73.

5. Dana D, Saguy IS. Review: Mechanism of oil uptake during deep fat frying and surfactant effect-theory and myth. Advances in Colloid and Interface Sci. 2006; 128:267-72.

6. Duran M, Pedreschi F, Moyano P, et al. Oil partition in pretreated potato slices during frying and cooling. J Food Eng. 2007;81:257-65.

7. Pedreschi F. Frying of potatoes: physical, chemical and microstructural changes. Drying technology: An Inter J. 2012; 30:707-25.

8. Vinci RM, Mestdagh F, Meulenaer BD. Acrylamide formation in fried potato products - Present and future, a critical review on mitigation strategies. Food Chem. 2012;133:1138-54

9. Hua X, Wang $\mathrm{K}$, Yang $\mathrm{R}$, et al. Edible coatings from sunflower head pectin to reduce lipid uptake in fried potato chips. LWT-Food Sci. and Tech. 2015;62:1220-5.

10. Djousse L, Petrone AB, Gaziano JM. Consumption of fried foods and risk of heart failure in the physician' health study. J Am Heart Assoc. 2015;4:e001740.

11. Krokida MK, Oreopoulou V, Maroulis ZB. Water loss and oil uptake as a function of frying time. J Food Eng. 2000;44:39-46.

12. Debnath S, Bhat KK, Rastogi NK. Effect of pre-frying on kinetics of moisture loss and oil uptake during deep fat frying of chickpea flour-based snack food. LWT-Food Sci Tech. 2003;36:91-8.

13. Kita A, Lisinska G, Golubowska G. The effects of oils and frying temperatures on the texture and fat content of potato crisps. Food Chem. 2007;102:1-5.

14. Phule AS, Annapure US. Effect of coating of hydrocolloids on Chickpea (Cicer ariertinum L.) and green gram (Vigna 
radiata) splits during deep fat frying. Inter Food Res J. 2013;20:565-73.

15. Yang Y, Achaerandio I, Pujola M. Influence of the frying process and potato cultivar on the acrylamide formation in French fries. Food Control. 2016;62:216-23.

16. Kilincceker $O$. The behaviour of some vegetable-based materials used as edible coating on chicken nuggets. Food Technology and Biotechnology. 2011;49:243-73.

17. Ansarifar E, Mohebbi M, Shahidi F. Studying some physicochemical characteristics of crust coated with white egg and chitosan using a deep-fried model system. Food and Nutritional Sci. 2012;3:685-92.

18. Shallal P, Rajaei P, Asadollahi S. The effect of kind and temperature of oil used in deep fat frying on the amount of oil uptake. Inter J Biosci. 2014;5:331-41.

19. Gamble MH, Rice P. The effect of slice thickness on potato crisps yield and composition. J Food Eng. 1988;8:31-46.

20. Tajner-Czopek A, Figiel A, Barrachina AAC. Effects of potato strip size and pre-drying method on French fries quality. European Food Res and Tech. 2008;227:757-66.

21. Basuny AMM, Mustafa DMM, Shaker AM. Relationships between chemical composition and sensory evaluation of potato chips made from six potato varieties with emphasis on the quality of fried sunflower oil. World J Dairy and Food Sci. 2008;4:193-200.

22. Arafat S M. Air frying technique for produce of healthy fried potato strips. J Food and Nutrition Sci. 2014;2:200-06.

23. Pedreschi F, Moyano P. Oil uptake and texture development in fried potato slice. J Food Eng. 2005;70:557-63.

24. Pedreschi F, Moyano P, Santis N, et al. Physical properties of pre-treated potato chips. J Food Eng. 2007;79;1474-82.

25. Tran MTT, Chen XD, Southern C. Reducing oil content of fried potato crisps considerably using a 'sweet' pretreatment technique. J Food Eng. 2007;80:719-26.

26. Kizito KF, Youssef MM, Abdel-Aal MH, et al. Quality attributes of French fries: Factors affecting thereon - A review. Alexandria J Food Sci Tech. 2015;12:11-28.

27. Varela P, Fiszman SM. Hydrocolloids in fried foods. A review. Food Hydrocolloids, 2011;25:1801-12.

28. Garcia MA, Ferrero C, Bertola N, et al. Edible coating from cellulose derivatives to reduce oil uptake in fried products. Innovative Food Sci Emerging Tech. 2002;3:391-97.

29. Rimac-Brncic S, Lelas V, Rade D, et al. Decreasing oil absorption in potato strips during deep fat frying. J Food Eng. 2004;64:237-41.

30. Bajaj I, Singhal R. Gellan gum for reducing oil uptake in sev, a legume based product during deep-fat frying. Food Chem. 2007;104:1472-77.
31. Freitas DDGC, Berbari SAG, Prati P, et al. Reducing of fat uptake in cassava product during deep-fat frying. J Food Eng. 2009;94:390-94.

32. Singthong J, Thongkaew C. Using hydrocolloids to decrease oil absorption in banana chips. LWT-Food Sci Tech. 2009;42:1199-203.

33. Pahade PK, Sakhale BK. Effects of blanching and coating with hydrocolloids on reduction of oil uptake in French fries. Inter Food Res J. 2012;19: 697-9.

34. Izadi S, Ojagh SM, Rahmanifarah K, et al. Production of low-fat shrimps by using hydrocolloid coatings. J Food Sci Tech. 2015;52:6037-42.

35. Karimi N, Kenari RE. Functionality of coatings with salep and basil seed gum for deep fried potato strips. J American Oil Chemists' Society. 2015;93:243-50.

36. AOAC. Official methods of analysis of the AOAC international. 16th edition, 4th revision. 1998 AOAC, Gaithersburg, MD, USA.

37. Bligh EG, Dyer WJ. A rapid method of total lipid extraction and purification. Canadian J Biochemistry and Physiology. 1959;37:911-917.

38. IUPAC. Standard methods for the analysis of oils, fats and derivatives method 2.501 (7th edn.), Blackwell Scientific publications 1987, Oxford, UK.

39. Pokorny J, Dieffenbacher A. Determination of 2thiobarbituric acid value: direct method, results of a collaborative study and the standardized method. Pure and Applied Chem. 1989;61:1170-89.

40. Garayo J, Moreira R. Vacuum frying of potato chips. J Food Eng. 2002;55:181-91.

41. Koh E, Surh J. Food types and frying frequency affect the lipid oxidation of deep frying oil for the preparation of school meals in Korea. Food Chem. 2015;174:467-72.

42. Crosa MJ, Skerl V, Cadenazzi M, et al. Changes produced in oil during vacuum and traditional frying of potato strips. Food Chem. 2014;146:603-7.

\section{*Correspondence to:}

Mohamed Youssef

Department of Food Science and Technology

Faculty of Agriculture

University of Alexandria

El-Shatby, 21545, Alexandria

Egypt

Tel: +201005559609

E-mail:m_m_youssef@yahoo.com 